Special issue of the 3rd International Conference on Computational and Experimental Science and Engineering (ICCESEN 2016)

\title{
Production of Chromium Boride Layers on Carbon Steel with Conversion Treatment: Chromium Deposition + Diffusion Annealing
}

\author{
R. BoubaAyA ${ }^{a, *}$, Y. Benarioua ${ }^{b}$, O. Allaoui $^{a}$ And M. Djendel ${ }^{a}$ \\ ${ }^{a}$ Laboratoire Génie des Procédés, Université de Laghouat, BP 37G, Laghouat, Algeria \\ ${ }^{b}$ Département de Génie Mécanique, Faculté de Technologies, Université de M'Sila, BP 166, M'Sila 28000, Algeria

\begin{abstract}
The present study has been conducted in order to obtaining chromium boride layers on carbon steel using a conversion processing comprising the following steps: boriding treatment in order to increase the amount of boron atoms in the steel surface, deposition of a thin layer of pure chromium using electrolytic method, and finally an annealing treatment for boron diffusion and formation of boride layer until complete transformation of chromium layer. Depending on the method used (chromium deposition followed by boriding or boriding followed by chromium deposition) and the holding time, the partial or complete conversion is obtained as a result of the diffusion process. The role of the annealing temperature on transformation rates of chromium into chromium boride films was investigated. It is shown that for $1 \mathrm{~h}$ at $900^{\circ} \mathrm{C}$, the chromium layer is totally transformed. The scanning electron microscopy analysis and X-ray diffraction showed the presence of $\mathrm{CrB}$ and $\mathrm{CrB}_{2}$ chromium borides in addition of $\mathrm{FeB}$ and $\mathrm{Fe}_{2} \mathrm{~B}$ iron borides.
\end{abstract}

DOI: 10.12693/APhysPolA.132.541

PACS/topics: carbon steel, boriding, chromium plating, diffusion annealing, chromium boride

\section{Introduction}

In the past two decades, borides of transition metals coatings have proven to be one of the most effective materials to increase the service life of machine components, cutting tools and forming tools, especially to improve wear and corrosion resistance [1, 2]. Among these metal compounds, chromium boride presents the best chemical and mechanical behavior under severe conditions of use $[3,4]$. Recent research on chromium boride films emphasized their oxidation and corrosion resistance and suggested that they have great potential for replacing electroplated hard chromium as protective coatings $[5,6]$. Hard films of chromium borides can be obtained by physical vapor deposition (PVD) or thermo-reactive deposition/diffusion (TRD) technique. In the case of PVD films the thickness is generally much less than $10 \mu \mathrm{m}$ that renders them improperly too resist to high contact pressure and moreover their adhesion to the substrate is lower than that obtained with other types of coating techniques. The TRD coatings need very long treatment times at high temperatures. There are very common industrial methods that can be combined anyway to produce chromium boride coatings [7-9].

In order to produce a coating of high hardness, good adhesive properties and of sufficient thickness to resist severe conditions of loading, we suggest here an alternative technique based on a three-step process using only standard industrial methods. The first step has the objective

*corresponding author; e-mail: raboubaaya@yahoo.fr of increase of the boron content at the surface of the substrate using a standard boriding process. The second step is to coat the boronized sample with a layer of chromium. The last step is a thermal treatment at temperatures which would allow the diffusion of boron toward the surface of the material to combine with chromium to form chromium borides throughout the coating.

\section{Experimental methods}

\subsection{Materials and coating deposition}

The chemical composition of the substrate was determined by spectrometric analysis using a spectrometer H-T. To conduct a comparative study, we divided the samples into 2 groups:

- Group 1: samples preparation, boriding, coating with a chromium layer, heat treatment, characterization of obtained deposits.

- Group 2: samples preparation, coating with a chromium layer, boriding, heat treatment, characterization of obtained deposits.

TABLE I

Chemical composition of the steel to be coated [\%].

\begin{tabular}{c|c|c|c|c|c|c}
\hline \hline $\mathrm{Fe}$ & $\mathrm{C}$ & $\mathrm{Si}$ & $\mathrm{Mn}$ & $\mathrm{P}$ & $\mathrm{S}$ & $\mathrm{Cr}$ \\
95.99 & 0.19 & 0.22 & 0.94 & 0.003 & 0.056 & 1.12 \\
\hline $\mathrm{Mo}$ & $\mathrm{Ni}$ & $\mathrm{Al}$ & $\mathrm{Co}$ & $\mathrm{Cu}$ & $\mathrm{Ti}$ & $\mathrm{Sn}$ \\
0.07 & 1.18 & 0.0116 & 0.01 & 0.20 & 0.0012 & 0.010
\end{tabular}

The preparation of the substrate consists in a mechanical polishing on each sample using abrasive papers. The finishing operation provides a good polishing with 
felt washed down with a suspension of alumina in water. The polished surface must be cleaned thoroughly with water and dried with compressed air and hot filtered.

The boriding treatments were performed in an electric muffle furnace. The samples to be boronised are placed in an ordinary steel crucible with a lid. For a good efficiency of the boriding powder, the crucible cover was concealed by a clay paste. To ensure a good homogenization of cement throughout the volume, it is stirred for several minutes. The boriding treatment was conducted for a period of $4 \mathrm{~h}$ at a temperature of $900^{\circ} \mathrm{C}$. This treatment provides a boron-treated layer with a thickness of approximately $150 \mu \mathrm{m}[10,11]$.

Samples were chrome electroplating, the standard composition of plating bath: $250 \mathrm{~g} / 1 \mathrm{CrO}_{3}, 2.5 \mathrm{~g} / 1 \mathrm{SO}_{4} \mathrm{H}_{2}$, bath temperature $\left(40-44^{\circ} \mathrm{C}\right)$, antimony lead anode, retention time $1 / 2 \mathrm{~h}$ and deposition rate of about $40 \mu \mathrm{m} / \mathrm{h}$.

In order to obtain a chromium boride layer, samples were thermally annealed in the temperature of $950{ }^{\circ} \mathrm{C}$ [12]. The hold time is $2 \mathrm{~h}$.

\subsection{Characterization and analysis techniques}

Microscopic observation requires fine polishing of the surface to be observed. The surface was cleaned with acetone and dried by hot air flow. The second phase consists of a chemical attack using the product nital. The equipment used is a universal optical metallographic microscope ZEISS type. Cemented steel area, thickness of chromium layers deposited and annealed was measured by an optical micrometer associated to the optical microscope.

The hardness profile of the samples was measured along the cross-sections using a microdurometer type Buehler MICROMET (hardness tester). Three Vickers indentations using a load of $20 \mathrm{~g}$ for $15 \mathrm{~s}$ were performed at each depth in order to obtain a significant statistical value.

\section{Results and discussion}

\subsection{Morphology}

Metallographic analysis was used after being cut, polished, and attacked chemically samples. In most photos obtained, the upper part shows the deposition of chromium and/or chromium boride obtained by annealing, while the substrate occupies the lower part. Good surface preparation has led us to obtain a flat surface chromium or chromium boride after treatment.

Micrographs of polished and etched cross-sections of the coated samples are shown in Figs. 1 and 2. Three different regions were observed: (I) the outer layer composed of chromium (chromium oxide), (II) the inner layer composed of a mixture of chromium boride phases, and (III) the steel substrate [13].

Aspect final sample after annealing shows that the effect of corrosion is smaller for the boriding followed by chromium deposition than for chromium deposition followed by boriding.

From the viewpoint of the thickness of obtained layer, boriding followed by chromium deposition $(50 \mu \mathrm{m})$ is

better than chromium deposition followed by boriding (20 $\mathrm{mm})$.
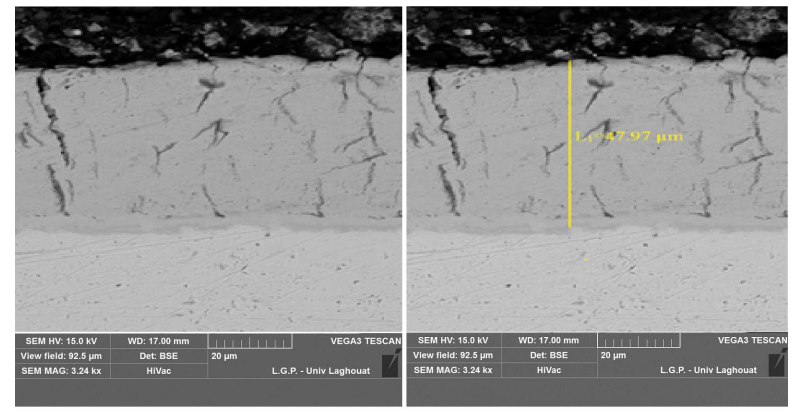

Fig. 1. Observation of layer/substrate (boriding deposition).

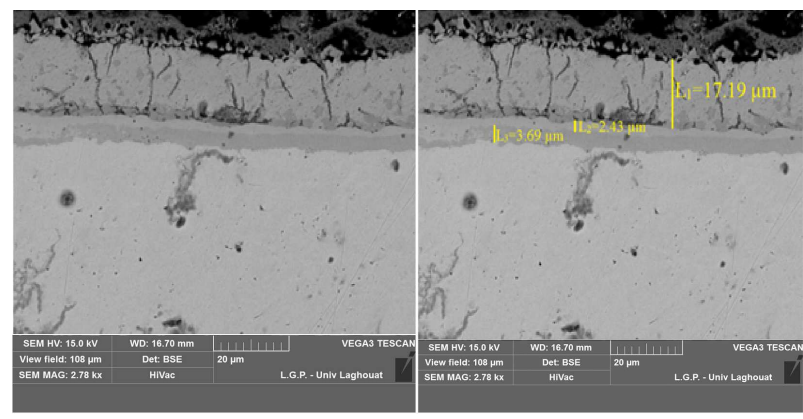

Fig. 2. Observation of metallographic faces layer/substrate (chromium deposition followed by boriding).

\subsection{Hardness}

Micro-hardness measurements at $20 \mathrm{~g}$ load were made on different areas of the formed layer on surface. The values of the microhardness depending on different areas and depending on the treatment carried out are given in Table II.

\section{TABLE II}

Microhardness recorded on different areas of the surface after conversion treatments.

\begin{tabular}{c|c|c}
\hline \hline Treatment & $\begin{array}{c}\text { Boriding }+\mathrm{Cr} \\
+ \text { annealing }\end{array}$ & $\begin{array}{c}\text { Cr }+ \text { boriding } \\
+ \text { annealing }\end{array}$ \\
\hline zone 1 & 1780 & 1670 \\
zone 2 & 865 & 850 \\
zone 3 & 240 & 235
\end{tabular}

According to the obtained values of micro-hardness (Table II), we can advance the following remarks [13]:

- Zone 1: this area corresponds to the chromium boride $\mathrm{CrB}_{2}$.

- Zone 2: corresponds to a transition zone where nonsoluble components in $\mathrm{CrB}_{2}$ boride are pushed. 
- Zone 3: corresponds to the initial substrate.

Indeed, we obtained a multilayer material with a microhardness gradient from the surface to the core of the substrate.

\section{Conclusion}

Whatever the treatment (chromium deposition followed by boriding or boriding followed by chromium deposition), conversion treatment have provided chromium borides layers on the treated samples. Indeed, for the transformations boriding followed by chromium deposition, the thickness is about $20 \mu \mathrm{m}$, while for transformations chromium deposition followed by boriding, the thickness is about $50 \mu \mathrm{m}$.

Hardness and adhesion of layers produced by annealing treatment were increased even for partial treatment where only partial transformation of chromium into chromium borides occurs.

The results obtained using the new methodology proposed in the present paper show that very simple and spread technologies such as case boronizing, electrolytic coating, and thermal treatment in air can lead to very hard and resistant coatings.

\section{References}

[1] C.L. Yeh, J.Z. Lin, H.J. Wang, Ceram. Int. 38, 5691 (2012).

[2] K. Hirota, K. Mitani, M. Yoshinaka, O. Yamaguchi, Mater. Sci. Eng. A 399, 154 (2005).
[3] A. Bosseboeuf, M.Sc. Thesis, Orsay 1989, p. 223.

[4] J.L. Vossen, W. Kern, Thin Film Processes, Academic Press, 1978.

[5] T. Sourmail, T. Okuda, J.E. Taylor, Scr. Mater. 50, 1271 (2004).

[6] D. Bouchier, Ph.D. Thesis, Orsay 1985, p. 122.

[7] C.Y. Wei, F.S. Chen, Mater. Chem. Phys. 91, 192 (2005).

[8] S. Sen, Mater. Des. 27, 85 (2006).

[9] E. Karıp, S. Aydin, M. Muratoğlu, Acta Phys. Pol. A 128, B-160 (2015).

[10] M. Richert, A. Mazurkiewicz, J. Smolik, J. Achiev. Mater. Manufact. Eng. 43, 154 (2010).

[11] O. Allaoui, N. Bouaouadja, G. Saindernan, Surf. Coat. Technol. 201, 3475 (2006).

[12] Y. Benarioua, M.Sc. Thesis, Polytechnic School, El Harrach 1993.

[13] P.A. Dearnley, T. Bell, Surf. Eng. 1, 203 (1985). 